\title{
Ionospheric variations over Indian low latitudes close to the equator and comparison with IRI-2012
}

\author{
P. Pavan Chaitanya ${ }^{1}$, A. K. Patra ${ }^{1}$, N. Balan ${ }^{2}$, and S. V. B. Rao $^{3}$ \\ ${ }^{1}$ National Atmospheric Research Laboratory (NARL), Gadanki 517112, India \\ ${ }^{2}$ National Institute of Polar Research, Tachikawa-shi, Tokyo, Japan \\ ${ }^{3}$ Department of Physics, Sri Venkateswara University, Tirupati 517502, India
}

Correspondence to: A. K. Patra (akpatra@narl.gov.in)

Received: 29 May 2015 - Revised: 24 July 2015 - Accepted: 28 July 2015 - Published: 13 August 2015

\begin{abstract}
In this paper, we analyze daytime observations of the critical frequencies of the $\mathrm{F} 2(f o \mathrm{~F} 2)$ and $\mathrm{F} 3(f o \mathrm{~F} 3)$ layers based on ionosonde observations made from Indian low latitudes close to the magnetic equator and study their local time, seasonal, planetary-scale variations (including the solar rotation effect), and solar activity dependence. Given the occurrence of the F3 layer, which has remarkable local time, seasonal and solar activity dependences, variations in $f o \mathrm{~F} 2$ have been evaluated. Local time variations in $f o \mathrm{~F} 2$ and $f o \mathrm{~F} 3$ show noon "bite-out" in all seasons and in all solar activity conditions, which are attributed to vertically upward plasma transport by the zonal electric field and meridional neutral wind. Comparison of observed $f o \mathrm{~F} 2$ with those of the IRI-2012 model clearly shows that the model values are always higher than observed values and the largest difference is observed during noontime owing to the noon bite-out phenomenon. Peak frequency of the F layer $(f o \mathrm{~F} 2 / f o \mathrm{~F} 3)$, however, is found to have better agreement with IRI-2012 model. Seasonal variations of $f o \mathrm{~F} 2$ and $f o \mathrm{~F} 3$ show stronger asymmetry at the solstices than at the equinoxes. The strong asymmetry at the solstice is attributed to the asymmetry in the meridional neutral wind with a secondary contribution from $\mathbf{E} \times \mathbf{B}$ drifts, and the relatively weak asymmetry observed at the equinox is attributed to the asymmetry in $\mathbf{E} \times \mathbf{B}$ drifts. Variations in $f o \mathrm{~F} 2$ and $f o \mathrm{~F} 3$ with solar flux clearly show the saturation effect when $F_{10.7}$ exceeds $\sim 120$ sfu, which is different from that of the mid-latitudes. Irrespective of solar flux, both $f o \mathrm{~F} 2$ and $f o \mathrm{~F} 3$ in summer, however, are found to be remarkably lower than those observed in other seasons. Variations in $f o \mathrm{~F} 2$ show dominant periods of $\sim 27, \sim 16$ and $\sim 6$ days. Intriguingly, amplitudes of $\sim 27$-day variations in $f o \mathrm{~F} 2$ are found to be maximum in low solar activity
\end{abstract}

(LSA), moderate in medium solar activity (MSA) and minimum in high solar activity (HSA), while the amplitudes of $\sim 27$-day variations in $F_{10.7}$ are minimum in LSA, moderate in MSA and maximum in HSA. These results are presented and discussed in light of current observational and modelbased knowledge on the variations of low-latitude $f o \mathrm{~F} 2$ and foF3.

Keywords. Ionosphere (equatorial ionosphere)

\section{Introduction}

The Earth's ionosphere exhibits complex variabilities with varying spatial and temporal scales. The influencing factors for the ionospheric variabilities are (a) solar ionizing flux, (b) neutral dynamics and electrodynamics, and (c) solar wind conditions. The solar flux, which varies with the 11-year solar cycle, quasi 27-day rotation of the sun, day-to-day and even shorter timescales, has direct control on the plasma density in the ionosphere. The ionosphere is also controlled by the solar zenith angle, manifesting diurnal, annual and semiannual variations. Solar flux induced spatial and temporal variations in the neutral atmosphere lead to the thermospheric wind and electric field. In the low latitudes, the thermospheric wind and electric field, in conjunction with Earth's magnetic field, play an important role in the redistribution of plasma. In the recent past, it has also been recognized that significant variations in ionospheric parameters are governed by lower-atmospheric processes through complex coupling processes in the middle atmosphere (e.g., Abdu et al., 2006; Pancheva et al., 2006, Immel et al., 2006; Hagan et al., 2009; Chau et al., 2011). Neutral dynamical and 
electrodynamical forcing of in situ and lower-atmospheric origin jointly produces remarkable ionospheric variabilities with various spatial and temporal scales. At times, the ionosphere also turns unstable leading to unexpected variations. In addition to these, interaction of solar wind with the Earth's magnetic field manifests large variabilities in the ionosphere through both neutral dynamical and electrodynamical coupling. Thus, understanding of ionospheric variabilities from various perspectives, such as characterization, causative mechanisms and forecasting skill, continues to be one of the priority areas of aeronomy research.

With regard to the low-latitude ionosphere, variabilities in the $\mathrm{F}$ region have been given special attention due to their direct effects on communication/navigation systems. A large number of observational and modeling studies have been made to understand $\mathrm{F}$ region parameters, such as the critical frequency of the $\mathrm{F} 2$ layer, $f o \mathrm{~F} 2$ and the corresponding height, $h m \mathrm{~F} 2$, in terms of variabilities in solar flux, magnetic field, neutral dynamical/electrodynamical parameters (e.g., Forbes et al., 2000; Rishbeth and Mendillo, 2001; Dabas et al., 2006; Chen et al., 2010; Yadav et al., 2011; Ma et al., 2012). These studies have provided important inputs to the development of the International Reference Ionosphere (IRI) model (Bilitza, 2001, Bilitza and Reinisch, 2007; Bilitza et al., 2011, 2014), which is widely used by the aeronomy community across the world. Given the fact that the equatorial/low-latitude ionosphere is highly variable both spatially (both along longitude and latitude) and temporally, and with solar and geomagnetic activity, observations have revealed significant departure from the IRI model. With regard to the Indian sector, although some interesting studies addressing local time, seasonal and solar activity dependence of $f o \mathrm{~F} 2$ and $h m \mathrm{~F} 2$ have been made based on observations made from the magnetic equator and from locations close to or beyond the equatorial ionization anomaly crest (e.g., Chandra and Rastogi, 1971; Rajaram and Rastogi, 1977; Pasricha et al., 1987; Sharma et al., 1999; Sethi et al., 2003; Dabas et al., 2006; Yadav et al., 2010, 2011), no study has been made from locations in between the magnetic equator and the equatorial ionization crest to fully characterize low-latitude ionospheric variabilities. Moreover, these studies have not considered the F3 layer, which occurs frequently in the equatorial/low-latitude ionosphere (e.g., Pavan Chaitanya et al., 2012), while addressing the variabilities in the F2 layer parameters.

In this paper, we analyze the critical frequency of the $\mathrm{F}$ layer $(f o \mathrm{~F} 2$ and $f o \mathrm{~F} 3)$ observed during daylight hours (07:00-18:00 LT) from Sriharikota $\left(13.6^{\circ} \mathrm{N}, 80.2^{\circ} \mathrm{E}\right.$, magnetic latitude $6.5^{\circ} \mathrm{N}$ ), a low-latitude site in the Indian sector, and address their local time, seasonal and solar activity dependent variations. These include noon "bite-out", and equinoxial and solstice (summer and winter) asymmetries. Importantly, we consider the F3 layer properties while addressing the variabilities in $f o \mathrm{~F} 2$. We also address planetaryscale variations in $f o \mathrm{~F} 2$ and examine the solar flux at
$10.7 \mathrm{~cm}\left(F_{10.7}\right)$ and magnetic field in an effort to understand these variabilities. Further, we make a detailed comparison of $f o \mathrm{~F} 2 / f o \mathrm{~F} 3$ with the IRI-2012 model (Bilitza et al., 2014). Low-latitude ionospheric variabilities from Sriharikota or similar latitudes in the Indian sector have not been reported before and hence these results should be considered important to improve our understanding of the low-latitude ionospheric variabilities in the Indian sector in specific and the low-latitude ionosphere in general.

\section{Observational data}

This study is based on ionosonde observations made during daytime (07:00-18:00 LT) from Sriharikota $\left(13.6^{\circ} \mathrm{N}\right.$, $80.2^{\circ} \mathrm{E}$, magnetic latitude $6.5^{\circ} \mathrm{N}$ ), a low-latitude site in southern India. Observations used for the present study were made during 1995, which corresponds to low solar activity (LSA) conditions ( $F_{10.7}<75 \mathrm{sfu}$ ); 1998 and 2004, which correspond to medium solar activity (MSA) conditions during rising and declining phases ( $75 \mathrm{sfu}\left\langle F_{10.7}\right\rangle 125 \mathrm{sfu}$ ); and May 2002-April 2003, which corresponds to high solar activity (HSA) conditions $\left(F_{10.7}>125 \mathrm{sfu}\right)$. Ionosonde observations made on a quarter-hourly basis have been manually scaled to obtain $f o \mathrm{~F} 2$ and $f o \mathrm{~F} 3$ (corresponding to $\mathrm{F} 2$ and F3 layer peak electron densities). F3 layer parameters can be derived only when electron density of the F2 layer is smaller than that of F3. Observations during the major magnetic storms $(\mathrm{Ap}>40)$ have been excluded in statistical analysis.

Ground-based magnetic field observations used here were made during 1995, 2002 and 2004 from Tirunelveli $\left(8.7^{\circ} \mathrm{N}\right.$, $77.8^{\circ} \mathrm{E}$, dip lat. $0.4^{\circ} \mathrm{N}$ ), located close to the magnetic equator, and Alibag $\left(18.5^{\circ} \mathrm{N}, 72.9^{\circ} \mathrm{E}\right.$, dip lat. $\left.13.0^{\circ} \mathrm{N}\right)$, located well outside the electrojet belt $\left( \pm 3^{\circ}\right.$ magnetic latitude). The difference of observed magnetic fields from these stations, $\Delta H$ (i.e., $\Delta H_{\text {Tirunelveli }}-\Delta H_{\text {Alibag }}$ ), provides a measure of the equatorial electrojet, which has been used as a proxy for zonal electric field (e.g., Vikramkumar et al., 1987; Rastogi and Klobuchar, 1990; Anderson et al., 2002) to understand planetary-scale variabilities in $f o \mathrm{~F} 2$.

\section{Results and discussion}

\subsection{Local time and seasonal variations of $f o \mathrm{~F} 2$ and $f o F 3$ in different solar activity conditions}

Figure $1 \mathrm{a}$ and $\mathrm{b}$ present $f o \mathrm{~F} 2$ and $f o \mathrm{~F} 3$, respectively, as a function of local time (during 07:00-18:00 LT) and day of the year based on ionosonde observations made during 1995 (LSA), 1998 (MSA), 2002-2003 (HSA) and 2004 (MSA) (shown in the panels from top to bottom). It should be noted that for 2002-2003 observations, we have reorganized the data to plot from January to December so as to compare these results with those observed in other years. 

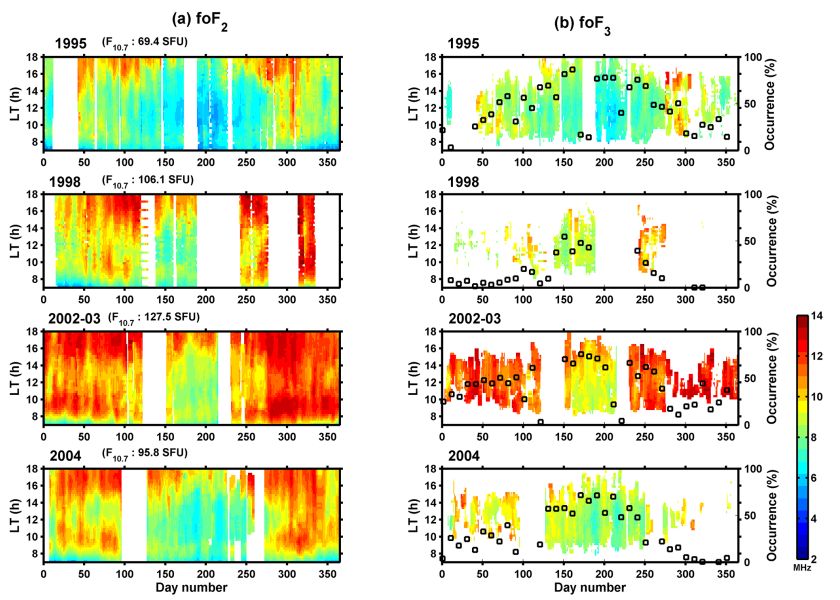

Figure 1. Local time variations of (a) $\mathrm{f}_{o} F_{2}$ and (b) $\mathrm{f}_{o} \mathrm{~F}_{3}$ as a function of day number observed in 1995, 1998, 2002-2003, and 2004 (from top to bottom panels). These observations correspond to different solar activity conditions (note the annual mean solar flux at $10.7 \mathrm{~cm}\left(F_{10.7 \mathrm{~cm}}\right)$ given in parentheses).

White portions in the figures represent data gaps. Black squares in each panel of Fig. $1 \mathrm{~b}$ represent occurrence rate of the F3 layer (in percent) in the respective year. Occurrence rate, $S$, has been computed based on quarter-hourly daytime observations made during a period of 10 consecutive days as $S=\left(N_{\mathrm{F} 3} / N_{\mathrm{o}}\right) \times 100$, where $N_{\mathrm{F} 3}$ and $N_{\mathrm{o}}$ represent the number of times the F3 layer was observed and the total number of observational runs in the 10-day period, respectively.

These results suggest that $f o \mathrm{~F} 2$ and $f o \mathrm{~F} 3$ are high in HSA, moderate in MSA and low in LSA as expected from solar flux dependence of the photoionization process. The occurrence rate of the F3 layer is found to vary from one year to another, with the occurrence rate being maximum in June-August (75-90\%), minimum in October-December $(10-40 \%)$ and moderate in other months (40-70\%). Seasonal dependence of the F3 layer occurrence shown here is similar to those reported earlier by Pavan Chaitanya et al. (2012) based on limited observations from the same location. Notwithstanding these detailed variations observed in different years, $f o \mathrm{~F} 2$ is found to have lower values during noon hours than those in the morning and late afternoon hours. This feature, however, is less conspicuous during October-December. Note that the local time in which $f o \mathrm{~F} 2$ values are low coincides with the occurrence of the F3 layer. Also note that this pattern is conspicuously present in all solar activity conditions. In the following, we present more details on the variations of $f o \mathrm{~F} 2$ and $f o \mathrm{~F} 3$.

\subsubsection{Local time variations in $f o \mathrm{~F} 2$ and $f o \mathrm{~F} 3$}

Figure 2 shows local time variations of $f o \mathrm{~F} 2, f o \mathrm{~F} 3$ and the difference of $f o \mathrm{~F} 3$ and $f o \mathrm{~F} 2, f o \mathrm{~F} 3-f o \mathrm{~F} 2$ in different seasons and different solar activity conditions. Since the
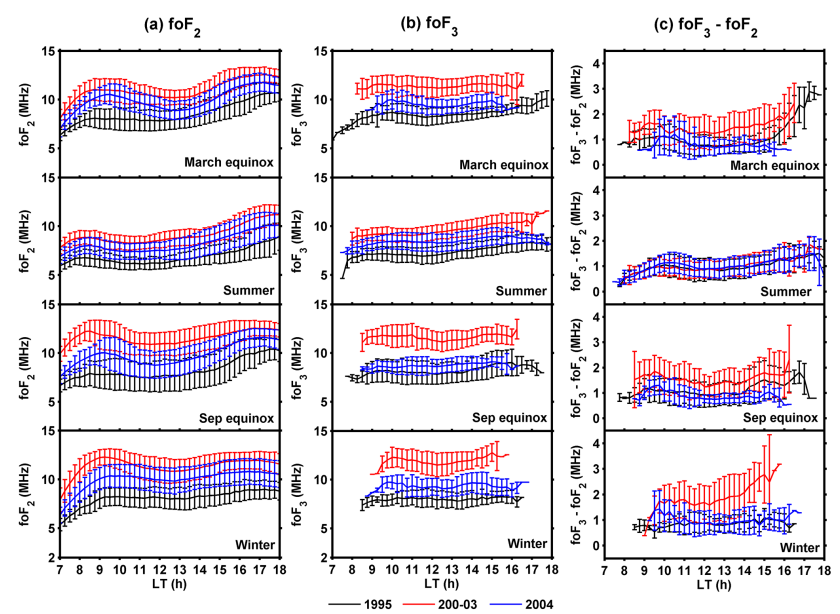

Figure 2. Local time variations in the mean and $\mathrm{SD}$ of (a) $f o \mathrm{~F}_{2}$, (b) $f o \mathrm{~F}_{3}$ and (c) $f o \mathrm{~F} 3-f o \mathrm{~F} 2$ in different seasons and different solar activity conditions. Results presented in red, blue and black correspond to 2002-2003 ( $\left.F_{10.7}>125 \mathrm{sfu}\right), 2004$ (125 sfu $\left.>F_{10.7}>75 \mathrm{sfu}\right)$ and $1995\left(F_{10.7}<75 \mathrm{sfu}\right)$.

F3 layer is formed by plasma transport, $f o \mathrm{~F} 3-f o \mathrm{~F} 2$ is expected to provide some insight into the local time variations of plasma transport. For seasonal analysis, we consider 10 February-9 May as March equinox, 10 May-9 August as summer, 10 August-9 November as September equinox, and 10 November -9 February as winter. Figure 2a, b and c show mean and standard deviation (SD) of $f o \mathrm{~F} 2, f o \mathrm{~F} 3$ and $f o \mathrm{~F} 3-f o \mathrm{~F} 2$, respectively, observed in different seasons (March equinox, summer, September equinox and winter) and different solar activity conditions. Results corresponding to 2002-2003 (HSA), 2004 (MSA) and 1995 (LSA) are presented in red, blue and black, respectively. Mean values of both $f o \mathrm{~F} 2$ and $f o \mathrm{~F} 3$ show clear variations with solar activity as well as season. Mean values of $f o \mathrm{~F} 2$ are found to be in the range of 5.5-14.5 MHz in HSA, 5-14.1 MHz in MSA, and $4.3-13.4 \mathrm{MHz}$ in LSA. Similarly mean values of $f o \mathrm{~F} 3$ are found to be in the range of $7.3-14.3 \mathrm{MHz}$ in HSA, 6.2$12.3 \mathrm{MHz}$ in MSA, and $4.6-12.7 \mathrm{MHz}$ in LSA. Variabilities (estimated as $\sigma / \mu \times 100 \%$, where $\sigma$ represents SD and $\mu$ represents mean) in $f o \mathrm{~F} 2$ are found to be in the range of $10-$ $15 \%$ and it is higher in the afternoon than forenoon in all seasons except for September equinox. Further, variations in $f o \mathrm{~F} 2$ are found to be minimum in HSA, moderate in MSA, and maximum in LSA. Variations in $f o \mathrm{~F} 3$ are found to be in the range of $5-10 \%$ and no significant seasonal and solar activity dependences have been noticed. As far as local time variations are concerned, both $f o \mathrm{~F} 2$ and $f o \mathrm{~F} 3$ show remarkable variations in almost all seasons and solar activity conditions. Notably, local time variations of $f o \mathrm{~F} 2$ show a conspicuous feature of noon bite-out in all solar activity conditions with decreasing values of $f o \mathrm{~F} 2$ with decreasing solar activity. The observed bite-out of $f o \mathrm{~F} 2$ is pronounced in equinoxes when compared to those in summer and winter. 
Notably, the noon values of $f o \mathrm{~F} 2$ are similar to those of early morning in almost all seasons and solar activity conditions.

The noon bite-out can also be noted in $f o \mathrm{~F} 3$ although it is not as noticeable as in $f o \mathrm{~F} 2$ due to the absence of the F3 layer in the morning and evening. Interestingly, a signature of noon bite-out can also be noted in $f o \mathrm{~F} 3-f o \mathrm{~F} 2$ and in all solar activity conditions. They are found to be in the range of $0.5-3 \mathrm{MHz}$ with larger values in the afternoon than in the morning.

Given the fact that noon bite-out of $f o \mathrm{~F} 2$ correlates well with the occurrence of the F3 layer in all seasons and solar activity conditions (as shown in Fig. 1), we examined whether the noon bite-out of $f o \mathrm{~F} 2$ is exclusively related to the occurrence of the F3 layer. We found (not shown here) that noon bite-out occurs even when the F3 layer is not observed. It is quite likely that some of these observations may be related to lower $f o \mathrm{~F} 3$ than $f o \mathrm{~F} 2$ and in such cases a ground-based ionosonde would not be able to probe the F3 layer.

A number of studies have been carried out in the past from the Indian low-latitude sector to study local time variations of $f o \mathrm{~F} 2$ (e.g., Rajaram and Rastogi, 1977; Rajaram, 1977; Sethi et al., 2003; Yadav et al., 2010). These studies showed the noon bite-out to occur close to the magnetic equator and not at latitudes greater than $10^{\circ} \mathrm{N}$. Although there were also some observations of forenoon bite-out of $f o \mathrm{~F} 2$ from the equatorial anomaly belt, the phenomenon was short lived (e.g., Sastri and Ramesh, 1982) and hence is very different from the noon bite-out reported here. The noon bite-out of $f o \mathrm{~F} 2$ has been attributed to the upward $\mathbf{E} \times \mathbf{B}$ drift of the F region plasma (e.g., Rajaram, 1977, and references therein). Present observations showed that the biteout of $f o \mathrm{~F} 2$ is closely associated with the occurrence of the F3 layer. Given the fact that the formation of the F3 layer is primarily governed by upward $\mathbf{E} \times \mathbf{B}$ drift with a secondary contribution from meridional wind (e.g., Balan et al., 1998), a close association observed between the noon bite-out of $f o \mathrm{~F} 2$ and occurrence of the $\mathrm{F} 3$ layer seems logical. As mentioned earlier, we have also found that the bite-out of $f o \mathrm{~F} 2$ occurs even when the F3 layer is not observed by ionosonde. In such a scenario it is quite likely that the F3 layer may be present at times, but is not visible with a ground-based ionosonde if $f o \mathrm{~F} 3$ (in the topside and topside ledge) is less than $f o \mathrm{~F} 2$. Given the fact that transport dominates over photochemistry at the $\mathrm{F} 2$ layer, the noon bite-out of $f o \mathrm{~F} 2$ during the presence of the F3 layer clearly indicates the upward motion of the F2 layer plasma resulting in bite-out of $f o \mathrm{~F} 2$.

The meridional neutral wind also plays an important role in transporting plasma along the magnetic field and this could influence the formation of the F3 layer as well as bite-out of $f o \mathrm{~F} 2$ at latitudes slightly away from the magnetic equator. For observations corresponding to Northern Hemisphere low latitudes, such as those presented here, the presence of transequatorial wind is expected to influence the distribution of $\mathrm{F}$ region plasma and the formation of the
F3 layer. For example, in the presence of vertical upward $\mathbf{E} \times \mathbf{B}$ drift while equatorward wind enhances vertical transport of plasma forming the F3 layer, poleward wind can enhance plasma diffusion process along the magnetic field inhibiting the formation of the F3 layer. An additional effect, however, could be caused by the upward $\mathbf{E} \times \mathbf{B}$ drift and poleward wind if the poleward wind exists at and above the F2 peak. While the upward $\mathbf{E} \times \mathbf{B}$ drift will push $\mathrm{F}$ region plasma upward causing a bite-out in density, plasma at altitudes around the F2 peak and above would diffuse along the magnetic field due to the poleward wind at that altitude. This process could easily inhibit the formation of the F3 layer. For low-latitude locations in the Northern Hemisphere, this effect is expected to be seen when meridional wind is northward. Such a scenario would occur in the Northern Hemisphere winter, although it is not a rule. It is important to recall that bite-out of $f o \mathrm{~F} 2$ varies with season and solar activity, implying that bite-out of $f o \mathrm{~F} 2$ is due to the united effect of upward $\mathbf{E} \times \mathbf{B}$ drift and meridional wind, which vary with local time, season and solar activity. A complete explanation of the observed features requires a modeling investigation using concurrent measurements of vertical $\mathbf{E} \times \mathbf{B}$ drift and meridional wind, which is beyond the scope of the present paper.

We have also noted noon bite-out of $f o \mathrm{~F} 3$, which has not been reported before. Earlier studies (e.g., Rajaram and Rastogi, 1977; Radicella and Adeniyi, 1999) suggested that the bite-out is pronounced around the F2 layer and it is due to the vertical transport of $\mathrm{F}$ region plasma. Total electron content observations have not revealed noon bite-out, suggesting that the noon bite-out is primarily related to the F2 layer (e.g., Lee, 2012, and references therein). Observations reported here clearly show that although the bite-out in $f o \mathrm{~F} 3$ is not as prominent as in $f o \mathrm{~F} 2$, it is also seen at the $\mathrm{F} 3$ layer, which is higher than that of the F2 layer. This finding is new and it would be interesting to understand under what conditions this bite-out occurs. Considering that vertical $\mathbf{E} \times \mathbf{B}$ drift, meridional wind and plasma diffusion along magnetic field line all are responsible for the plasma distribution in the $\mathrm{F} 2$ and F3 regions, it would also be interesting to see how the bite-out phenomenon varies with magnetic latitude. This aspect, however, is beyond the scope of the present investigation and we would like to address this aspect using suitable observations in future work.

\subsubsection{Comparison with the IRI-2012 model}

In an effort to examine to what extent the observed $f o \mathrm{~F} 2$ values agree or disagree with the IRI-2012 model values (Bilitza et al., 2014), we have compared the mean values of $f o \mathrm{~F} 2$ with those of the IRI model. A detailed comparison demonstrating variations with local time, season and solar activity is made in Fig. 3. Figure 3a, b and c show local time and seasonal variations of $f o \mathrm{~F} 2$ from observations and model corresponding to 1995 (LSA), 2004 (MSA) and 20022003 (HSA), respectively. These figures represent hourly val- 


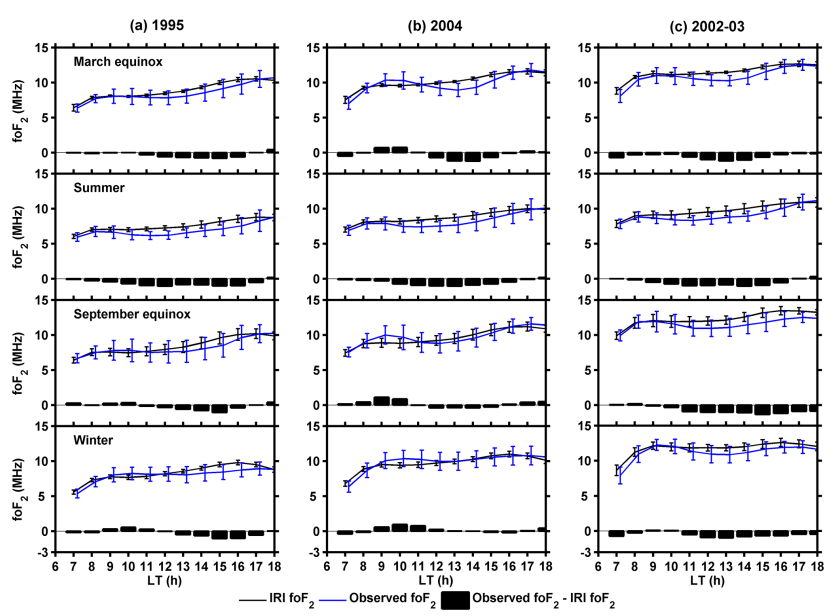

Figure 3. Local time variations of mean and SD of observed $f o \mathrm{~F} 2$ (blue) and IRI-2012 model $f o F 2$ (black) in different seasons (from top to bottom) in (a) 1995, LSA, (b) 2004, MSA, and (c) 20022003, HSA. Thick black vertical bars in each panel represent the difference of observed $f o \mathrm{~F} 2$ from IRI-2012 model $f o \mathrm{~F} 2$ (observed foF2-IRI-2012 model $f o \mathrm{~F} 2$ ).
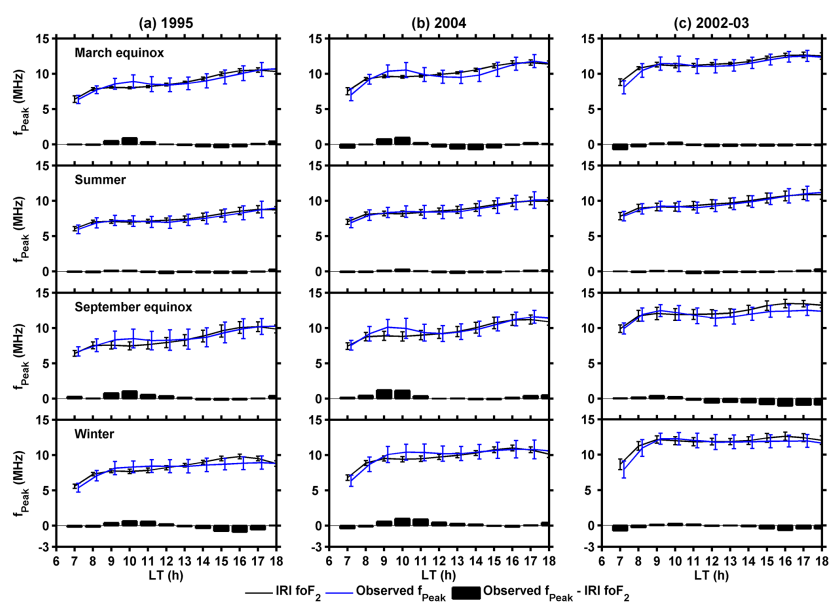

Figure 4. Same as Fig. 3, but for peak frequency (i.e., foF 2 ( foF 3$)$.

ues of observed (blue) and model (black) $f o \mathrm{~F} 2$ along with the differences ( $f o \mathrm{~F} 2_{\text {observed }}-f o \mathrm{~F} 2$ model $)$ in thick black bars. Results clearly show that observed $f o \mathrm{~F} 2$ values are mostly lower than those of the model (represented as negative values of $f o \mathrm{~F} 2_{\text {observed }}-f o \mathrm{~F} 2$ model $)$. Notably, the maximum difference (as high as $1.7 \mathrm{MHz}$ ) is found during noon hours and the difference is due to the observed noontime bite-out of $f o \mathrm{~F} 2$. This implies that observed $f o \mathrm{~F} 2$ values are smaller than those of IRI by $3.5 \times 10^{10}$ electron $^{-3}$.

Considering that the occurrence rate of the F3 layer is as high as $90 \%$ (in LSA summer) in the Indian low latitudes and the IRI model does not provide $f o \mathrm{~F} 3$, we have attempted to compare the observed peak frequency, i.e., $f o \mathrm{~F} 2$ or $f o \mathrm{~F} 3$, with IRI model $f o \mathrm{~F} 2$. Figure 4 shows a detailed
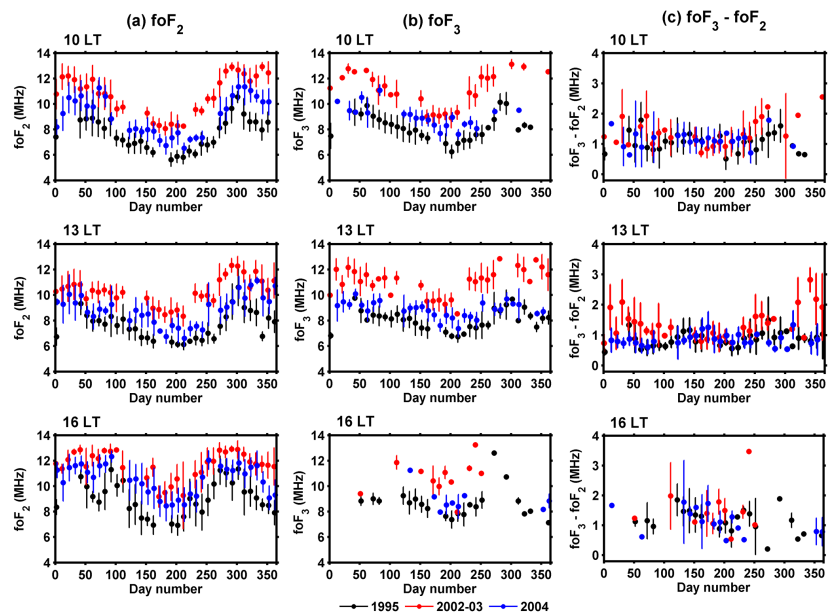

Figure 5. Seasonal variations of (a) $f o \mathrm{~F}_{2}$, (b) $f o \mathrm{~F}_{3}$, and (c) $f o \mathrm{~F}_{3}-$ $f o \mathrm{~F}_{2}$, shown in the form of mean and $\mathrm{SD}$, during different solar activity conditions (in different colors) observed at 10:00, 13:00 and 16:00 LT (top to bottom).

comparison similar to that done in Fig. 3, but for observed peak frequency $(f o \mathrm{~F} 2 / f o \mathrm{~F} 3)$ and IRI $f o \mathrm{~F} 2$. It is interesting to note that the difference between the two diminishes considerably. The maximum difference is found to be $1 \mathrm{MHz}$, which corresponds to a difference in electron density of $1.24 \times 10^{10}$ electron $\mathrm{m}^{-3}$. Notably, the difference during noon is found to disappear, implying that the IRI model represents the peak $\mathrm{F}$ layer frequency better. However, we find that the difference is positive (negative) in the forenoon (afternoon), which means that observed peak frequencies are higher (lower) in the forenoon (afternoon) than those of the model.

Lee et al. (2008) compared $f o \mathrm{~F} 2$ observations made from Jicamarca during low solar activity conditions of 1996 with those of IRI-2001 model. Later, Lee and Reinisch (2012) compared $f o \mathrm{~F} 2$ observations made from Jicamarca during low solar activity conditions of 2008-2009 with those of IRI2007. Both Lee et al. (2008) and Lee and Reinisch (2012) found that the difference between observed and model values are both positive and negative and the difference is $5 \times 10^{10}$ electron $\mathrm{m}^{-3}$. Their results also show observed values are higher (lower) in the forenoon (afternoon) than those of the model. In our observations, however, we find that the observed $f o \mathrm{~F} 2$ values are mostly smaller than those of the model irrespective of local time. In the case of peak $\mathrm{F}$ layer frequency, our results are found to be similar to Lee et al. (2008) and Lee and Reinisch (2012).

\subsubsection{Seasonal variations of $f o \mathrm{~F} 2$ and $f o \mathrm{~F} 3$}

To illustrate seasonal variations we show mean and SDs of $f o \mathrm{~F} 2, f o \mathrm{~F} 3$, and $f o \mathrm{~F} 3-f o \mathrm{~F} 2$ in Fig. $5 \mathrm{a}, \mathrm{b}$ and c, respectively, for three local times, viz., 10:00, 13:00 and 16:00 LT (shown from top to bottom) as a function of day number. 

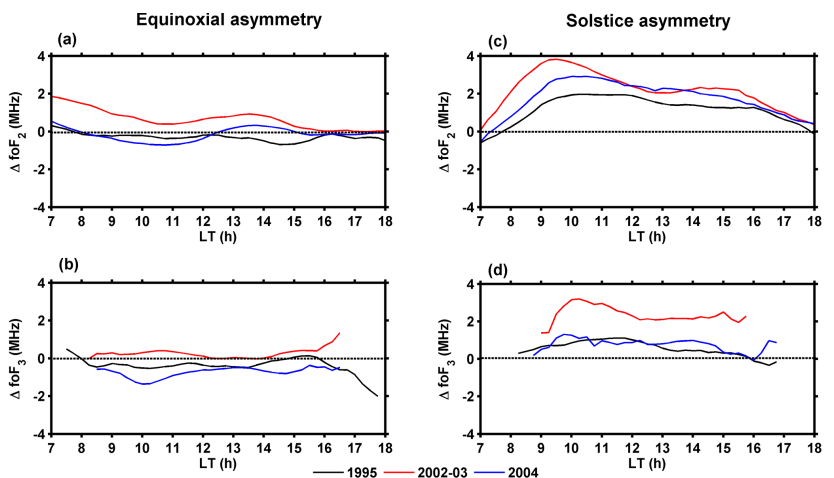

Figure 6. Equinoxial asymmetry (September equinox-March equinox) in (a) $f o \mathrm{~F}_{2}$ and (b) $f o \mathrm{~F}_{3}$, and solstice asymmetry (winter-summer) in (c) $f o \mathrm{~F}_{2}$, (d) $f o \mathrm{~F}_{3}$ in different solar activity conditions.

Observations made in 2002-2003 (HSA), 2004 (MSA), and 1995 (LSA) are shown in red, blue and black, respectively. These figures clearly show large values in HSA, moderate values in MSA and small values in LSA as expected from variations in solar ionization flux. Most importantly, $f o \mathrm{~F} 2$ and $f o \mathrm{~F} 3$ are found to be minimum in summer, moderate in winter, and maximum in equinoxes and these features are apparent in all solar activity conditions. Variations in $f o \mathrm{~F} 3-$ $f o \mathrm{~F} 2$ are found to be in the range of $0.5-2 \mathrm{MHz}$ and these do not show any noticeable seasonal and solar activity dependent patterns except for the fact that the differences in $f o \mathrm{~F} 3$ and $f o \mathrm{~F} 2$ at 13:00 LT are somewhat higher in HSA than those in MSA/LSA. Considerable equinoxial and solstice asymmetry in $f o \mathrm{~F} 2$ and $f o \mathrm{~F} 3$, however, can be noticed, which are addressed in the following.

\subsubsection{Equinoxial and solstice asymmetries}

Equinoxial asymmetry in $f o \mathrm{~F} 2(f o \mathrm{~F} 3)$ is estimated as $\Delta f o \mathrm{~F} 2_{\text {equinox }}=f o \mathrm{~F} 2_{\text {Autumn }}-f o \mathrm{~F} 2_{\text {Spring }} \quad\left(\Delta f o \mathrm{~F} 3_{\text {equinox }}=\right.$ $\left.f o \mathrm{~F} 3_{\text {Autumn }}-f o \mathrm{~F} 3_{\text {Spring }}\right)$. Similarly solstice asymmetry in $f o \mathrm{~F} 2(f o \mathrm{~F} 3)$ is estimated as $\Delta f o \mathrm{~F} 2_{\text {solstice }}=f o \mathrm{~F} 22_{\text {Winter }}{ }^{-}$ $f o \mathrm{~F} 2_{\text {Summer }} \quad\left(\Delta f o \mathrm{~F} 3_{\text {solstice }}=f o \mathrm{~F} 3_{\text {Winter }}-f o \mathrm{~F} 3_{\text {Summer }}\right)$. Equinoxial asymmetries in $f o \mathrm{~F} 2$ and $f o \mathrm{~F} 3$ are shown in Fig. $6 \mathrm{a}$ and $\mathrm{b}$, and solstice asymmetries in $f o \mathrm{~F} 2$ and $f o \mathrm{~F} 3$ are shown in Fig. 6c and d, respectively. Different colors represent results corresponding to different solar activity conditions (HSA, MSA and LSA). These figures suggest that while $f o \mathrm{~F} 2$ is generally higher in the September equinox in HSA and MSA, it is either higher in the March equinox or equal to that of September equinox in LSA. In the case of $f o \mathrm{~F} 3$, however, no significant difference is noticed. Solstice asymmetries in both $f o \mathrm{~F} 2$ and $f o \mathrm{~F} 3$, however, are found to be very different from those in the equinox. Both $f o \mathrm{~F} 2$ and $f o \mathrm{~F} 3$ are higher in winter than in summer. We also note that the asymmetry is more in HSA and moderate in MSA and LSA.
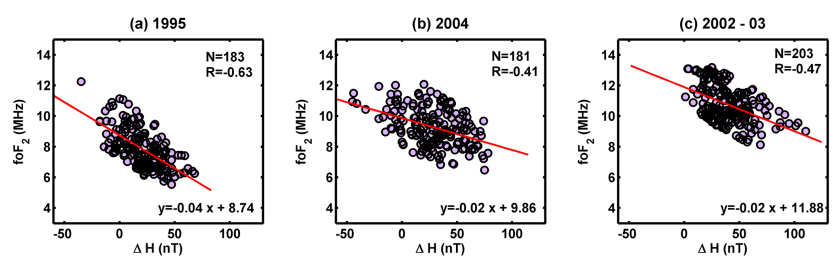

Figure 7. Scatter plot of $\Delta H$ vs. $f o F_{2}$ showing relationship between these parameters in (a) 1995, (b) 2004 and (c) 2002-2003.

Ionospheric plasma density not only depends on solar activity, but also on transport. In the low latitudes two important drivers of plasma transport are the $\mathbf{E} \times \mathbf{B}$ drift and neutral wind. In the summer and winter as compared to the equinox, the meridional neutral wind is expected to significantly contribute to plasma transport via the magnetic field lines. Considering that large vertical $\mathbf{E} \times \mathbf{B}$ drift can significantly reduce the F2 layer density and form an additional layer (the F3 layer), we would expect an inverse relationship between vertical $\mathbf{E} \times \mathbf{B}$ drift and $f o \mathrm{~F} 2$. In order to gain some insight into this phenomenon, we have used $\Delta H$ data as proxy of $\mathbf{E} \times \mathbf{B}$ drift (Anderson et al., 2002; Patra et al., 2014) and examined the relationship between $\Delta H$ and $f o \mathrm{~F} 2$. Figure 7 shows scatter plots displaying the relationship between the two in different solar activity conditions. All figures show an inverse relationship between the two parameters. In an earlier study, Rastogi et al. (1972) found a similar relationship between $\Delta H$ and $f o \mathrm{~F} 2$ based on $f o \mathrm{~F} 2$ observations made at Kodaikanal and Ahmedabad. This implies that if seasonal variation exists in $\mathbf{E} \times \mathbf{B}$ drift, it would account for the asymmetry in $f o \mathrm{~F} 2$. This, however, would be more applicable in the equinoxes when we do not expect a large meridional wind. Patra et al. (2012) showed that in the Indian sector, $\mathbf{E} \times \mathbf{B}$ drift is higher in the March equinox than in September equinox and higher in the winter than in the summer. This is expected to result in low values of $f o \mathrm{~F} 2$ in March equinox and winter and large values in September equinox and summer. The results show that while the equinoxial observations are consistent with the forcing effect of $\mathbf{E} \times \mathbf{B}$ drift, the solstice observations are not. This implies that at the solstice, the meridional neutral wind plays an important role in the plasma distribution. The present observations clearly suggest that the winter anomaly (larger values of $f o \mathrm{~F} 2$ in winter than in summer) must be linked with large values of poleward wind in winter.

In summer/winter, however, the meridional neutral wind could play a significant role in plasma distribution. For example, in the Northern Hemisphere winter, meridional wind is expected to be poleward and such wind is expected to push F2 region plasma downward, inhibiting the formation of the F3 layer, which in turn may result in poleward enhancement in $f o F 2$. In the Northern Hemisphere summer, however, meridional neutral wind is expected to be equatorward and this is expected to push F2 region plasma upward, form- 
ing the F3 layer, which may result in reduction in $f o \mathrm{~F} 2$. The actual meridional winds, however, could be different from the expected directions, and including their magnitude and such variations in the meridional wind in conjunction with the vertical $\mathbf{E} \times \mathbf{B}$ drift could result in variations in the $\mathrm{F} 2$ and F3 layer parameters.

\subsection{Solar activity dependence}

Figure $8 \mathrm{a}, \mathrm{b}$ and $\mathrm{c}$ show seasonal mean and SD of $f o \mathrm{~F} 2$, foF3 and $f o \mathrm{~F} 3-f o \mathrm{~F} 2$, respectively, observed at 13:00 LT in different years (i.e., 1995, 1998, 2002-2003, and 2004) along with solar activity in terms of $F_{10.7}$. Results corresponding to different seasons are shown in different colors. Both $f o \mathrm{~F} 2$ and $f o \mathrm{~F} 3$ increase with solar activity (represented by $F_{10.7}$ ). We also note that both $f o F 2$ and $f o F 3$ observed in summer (shown in red) are remarkably lower than those observed in other seasons. Variations in $f o \mathrm{~F} 3-f o \mathrm{~F} 2$, however, do not show any systematic pattern. For more clarity on the solar dependence of these parameters, we present mean and SDs of $f o \mathrm{~F} 2, f o \mathrm{~F} 3$ and $f o \mathrm{~F} 3-f o \mathrm{~F} 2$ as a function of $F_{10.7}$ in Fig. 8d, e and f, respectively. Note that observations shown in red correspond to summer and those shown in blue correspond to other seasons (winter and equinoxes). It is very clear from these figures that both $f o \mathrm{~F} 2$ and $f o \mathrm{~F} 3$ are smaller in summer than those in other seasons and thus we have fitted summer observations separately to distinguish the summertime features from those observed in other seasons. Despite the differences in $f o \mathrm{~F} 2$ and $f o \mathrm{~F} 3$ observed in summer and in other seasons, all $f o \mathrm{~F} 2$ and $f o \mathrm{~F} 3$ are found to increase with $F_{10.7}$ up to a value of $\sim 120$ sfu and saturate afterwards. This implies that in 2002-2003, F layer critical frequencies did not increase much with solar flux.

Similar variations have been observed at other local times as well (not shown) except for the fact that $f o \mathrm{~F} 2$ is the highest at $\sim 16: 00 \mathrm{LT}$, moderate at $\sim 10: 00 \mathrm{LT}$ and lowest at $\sim$ 13:00 LT at all solar activity conditions. Nearly similar features were noted in $f o \mathrm{~F} 3$ although local time variations are not as great as observed in $f o \mathrm{~F} 2$. Low values of $f o \mathrm{~F} 2$ and foF3 during 13:00 LT are consistent with those observed as noon bite-out, which is linked with vertical transport of $F$ region plasma, presumably governed by vertical $\mathbf{E} \times \mathbf{B}$ drift. Given the fact that both $f o \mathrm{~F} 2$ and $f o \mathrm{~F} 3$ display noon biteout, modeling of $f o \mathrm{~F} 2$ and $f o \mathrm{~F} 3$ as a function of solar flux would require knowledge of $\mathbf{E} \times \mathbf{B}$ drift, which varies with longitude, latitude and season.

Solar activity dependence of low-latitude ionospheric $f o \mathrm{~F} 2$ has been studied earlier based on observations made from three stations (Kodaikanal, Ahmedabad and Delhi) in the Indian sector (e.g., Yadav et al., 2011). They also found saturation in $f o F 2$ for high values of $F_{10.7}(>120 \mathrm{sfu}$ ) similar to that shown here. They found that at the equatorial station Kodaikanal $f o \mathrm{~F} 2$ values in equinoxes are roughly equal to or slightly higher than those in winter and the winter values of foF 2 are always higher than those of summer. With regard
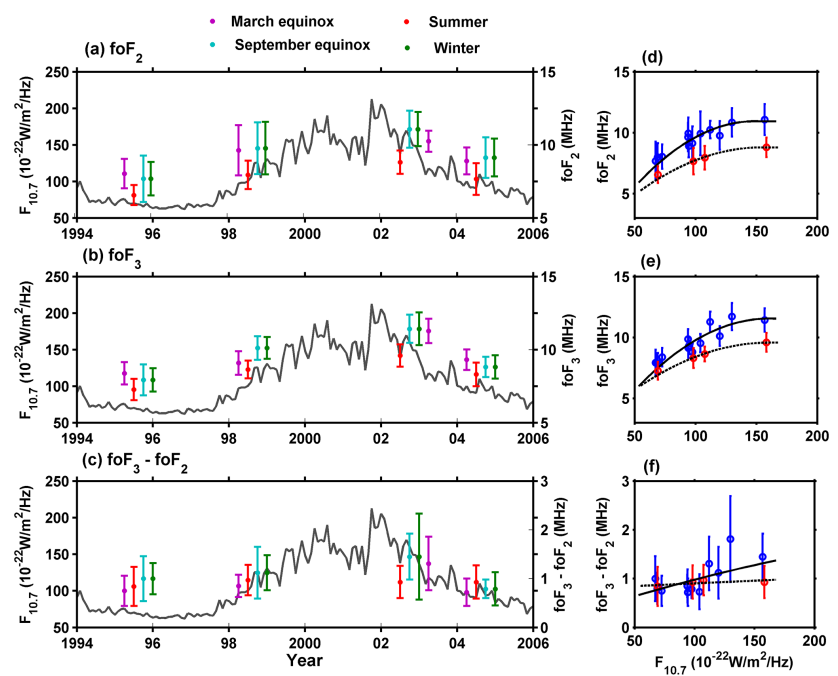

Figure 8. Seasonal mean and $\mathrm{SD}$ of (a) $f o \mathrm{~F}_{2}$ and (b) $f o \mathrm{~F}_{3}$ (c) $f o \mathrm{~F}_{3}-f o \mathrm{~F}_{2}$ overlaid by $F_{10.7}$ to show solar activity dependence. Note the colors representing different seasons. Right side panels show correlations between (d) $f o \mathrm{~F}_{2}$, (e) $f o \mathrm{~F}_{3}$ and (f) $f o \mathrm{~F}_{3}-$ $f o \mathrm{~F}_{2}$ with $F_{10.7}$ including the best fit lines. Data points shown in red correspond to summer since they are different from those observed in other seasons.

to the off-equatorial observations, they found that while over Ahmedabad the $f o \mathrm{~F} 2$ values in equinoxes are roughly equal to or higher than those at the solstices, over Delhi they are higher than those of solstices. They have also found that during some period, the winter values of $f o \mathrm{~F} 2$ are higher than those of summer. We found that $f o \mathrm{~F} 2$ values in winter solstice are similar to those of equinoxes and $f o \mathrm{~F} 2$ values in summer are always lower than those of equinoxes and winter. It should be noted that the observations used in this study were made from Sriharikota, which is located at a latitude higher than that of Kodaikanal and much lower than those of Ahmedabad and Delhi. The observed difference could be related to the dynamical and electrodynamical effects on $f o \mathrm{~F} 2$ owing to the difference in latitude. It should be noted that most of the earlier studies were based on $f o \mathrm{~F} 2$. In the present study, we show that $f o \mathrm{~F} 3$ also shows similar saturation for $F_{10.7}>120$ sfu. Balan et al. (1994) used ionospheric electron content (IEC) to study variation of ionospheric ionization with solar flux and found the saturation effect in IEC. The saturation effect was very clear for $F_{10.7}>200 \mathrm{sfu}$ and at times for $F_{10.7}>150 \mathrm{sfu}$. They found that this saturation is due to the nonlinear relationship between $F_{10.7}$ and solar Xrays, extreme ultraviolet and Lyman- $\alpha$ fluxes for high values of $F_{10.7}$. In the present observations, however, we find the saturation effect for $F_{10.7}>120 \mathrm{sfu}$. It is important to mention that Balan et al. (1994) used IEC data from stations well beyond the equatorial/low-latitude region (19.6-58.6 ${ }^{\circ} \mathrm{mag}$ netic latitude). The present and earlier observations from Indian low latitudes clearly suggest that the saturation effect in 

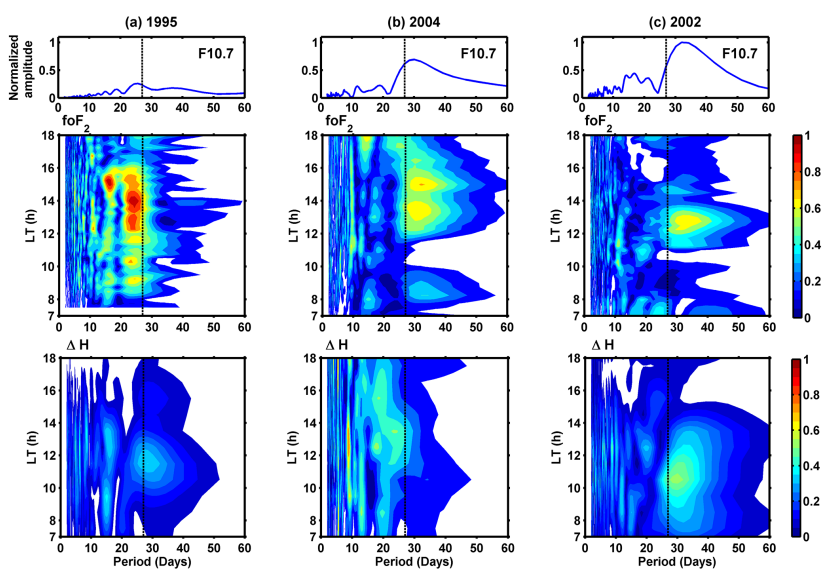

Figure 9. Spectral results, presented in terms of periods, of $F_{10.7}$, $f o \mathrm{~F} 2$ and $\Delta H$ observations corresponding to (a) 1995 (LSA), (b) 2004 (MSA) and (c) 2002 (HSA). Data between day numbers 270 and 365 in each year, a period when continuous observations of $f o \mathrm{~F} 2$ were available, have been used. Results on $F_{10.7}$ are obtained based on daily values, while those of $f o \mathrm{~F} 2$ and $\Delta H$ are based on daily values taken at a $1 \mathrm{~h}$ interval during 07:00-18:00 LT.

the F layer critical frequency occurs at lower values of solar flux than that in mid-latitude. It is quite likely that the saturation effect reported here for low latitudes is due to the ubiquitous presence of dynamical and electrodynamical forcing on plasma density distribution. The role of vertical transport on the noon bite-out of $f o \mathrm{~F} 2$ and $f o \mathrm{~F} 3$ seems to support this viewpoint although this needs to be ascertained through further study.

\subsection{Planetary-scale variations in $f o F 2$ and solar rotation effect}

To study planetary-scale variations including the solar rotation effect, we limit our study to $f o \mathrm{~F} 2$ since the $\mathrm{F} 3$ layer is not observed continuously. We have analyzed $f o \mathrm{~F} 2, F_{10.7}$, and $\Delta H$ data to examine the effects of solar rotation and electrodynamical forcing on the $f o \mathrm{~F} 2$ variability. $\Delta H$ data have been used due to the unavailability of $\mathbf{E} \times \mathbf{B}$ drift observations in the Indian sector. Since we have data breaks in $f o \mathrm{~F} 2$, we have performed both fast Fourier transformation (FFT) and Lomb-Scargle periodogram analysis to examine the dominant period present in $F_{10.7}, f o \mathrm{~F} 2$ and $\Delta H$. Both analyses show similar periods present in the data sets but their amplitudes were better represented in the FFT spectrum. Thus to examine the dominant periods and their amplitudes present in different solar activity conditions, we opted for FFT and performed spectral analysis on daily values of $F_{10.7}, f o \mathrm{~F} 2$ and $\Delta H$ data between day numbers 270 and 365 , a period when continuous observations of $f o \mathrm{~F} 2$ were available in all the three years. Spectral results are shown in the form of period (instead of frequency) one below the other for 1995, 2004 and 2002 in Fig. 9a, b and c, respectively.
Note that spectral data of $f o \mathrm{~F} 2$ and $\Delta H$ have been computed at an hourly interval during 07:00-18:00 LT. Amplitudes of the FFT spectra of $F_{10.7}, f o \mathrm{~F} 2$ and $\Delta H$ are normalized to the peak amplitude observed in 2002, 1995, and 2002, respectively to make a comparative assessment. Vertical dashed lines in each panel are drawn to mark the 27-day solar rotation period. Spectra of $F_{10.7}$ clearly show a dominant peak with period of $\sim 25$ days in 1995, $~ 30$ days in 2004 and $\sim 32$ days in 2002, presumably linked with the solar rotation period of $\sim 27$ days. Peak spectral amplitudes, however, are different in different solar activity conditions: maximum in 2002 (HSA), moderate in 2004 (MSA) and minimum in 1995 (LSA). There are other spectral peaks with periods of 13, 16 and 20 days as well, but they are less pronounced. Spectral data of $f o \mathrm{~F} 2$ also show dominant peaks with periods of $\sim 25$ days in 1995, 30 days in 2004 and $\sim 32$ days in 2002 , very similar to those observed in $F_{10.7}$. Variations in $f o \mathrm{~F} 2$ with these periods, however, are not present at all local times. They are observed almost during the entire day in 1995, during 08:00-10:00 and 12:00-16:00 LT in 2004, and during 11:00-14:00 LT in 2002. Peak amplitude in $f o F 2$ variations is found to be maximum in 1995 followed by 2004 and 2002. In addition, shorter periods, which include $\sim 16$ days, $\sim 10$ days and $\sim 6$ days, can also be noted. Again these periods are not always present. Spectral data of $\Delta H$ show a dominant period of $\sim 27$ days during 1995, 20-25 days in 2004 and $\sim 30$ days in 2002. Shorter periods ( $\leq 16$ days) are also present. It is interesting to note that dominant periods in $\Delta H$ do not match with those of $f o \mathrm{~F} 2$ except for 2002, where the periodicity in $\Delta H$ ( $\sim 30$ days) is close to that of $f o \mathrm{~F} 2$ ( $\sim 32$ days). This implies that while $f o \mathrm{~F} 2$ variations have a closer relationship to $F_{10.7}$ they are poorly related to those in $\Delta H$ except for 2002. We recall that in 2002, $f o \mathrm{~F} 2$ did not increase with solar flux due to saturation effect and also the amplitude of 32-day variability in $f o \mathrm{~F} 2$ was unlike that of $F_{10.7}$. Thus the 32-day variabilities observed in $f o \mathrm{~F} 2$ could partly be due to the electrodynamical effect (as seen in $\Delta H$ variations). Further investigation is required to understand the effect of solar rotation on $f o \mathrm{~F} 2$.

\section{Summary}

Important results on the variations of $f o \mathrm{~F} 2$ and $f o \mathrm{~F} 3$ can be summarized as follows:

1. Low-latitude $\mathrm{F} 2$ layer critical frequency $(f o \mathrm{~F} 2)$ is directly related to the formation of the F3 layer, which varies remarkably with season and solar activity. Observations show that the occurrence rate of the F3 layer is maximum in June-August, minimum in OctoberDecember and moderate in other months and these have direct influence on $f o \mathrm{~F} 2$.

2. Local time variations in $f o \mathrm{~F} 2$ show remarkable noon bite-out in all seasons in HSA and MSA and somewhat less evident in LSA. Local time variations in $f o \mathrm{~F} 3$ also 
show noon bite-out, but it is less prominent when compared to $f o \mathrm{~F} 2$.

3. Comparison of observed $f o \mathrm{~F} 2$ with those of the IRI2012 model clearly shows that the model values are always higher than those of observations and the largest difference is observed during noontime, which is linked with the noon bite-out phenomenon. Peak frequency ( $f o \mathrm{~F} 2$ or $f o \mathrm{~F} 3$ ), however, is found to agree better with the IRI-2012 model values.

4. Seasonal variations of $f o \mathrm{~F} 2$ and $f o \mathrm{~F} 3$ show stronger asymmetry at the solstice than at equinox. Anticorrelation between $f o \mathrm{~F} 2 / f o \mathrm{~F} 3$ and $\Delta H$ suggests that vertical plasma drift due to the zonal electric field plays a role in the observed asymmetries. In the solstices, however, the importance of the meridional neutral wind looks to be more important than the zonal electric field.

5. Variations in $f o \mathrm{~F} 2$ and $f o \mathrm{~F} 3$ with solar flux clearly show the saturation effect irrespective of season when $F_{10.7}$ exceeds $\sim 120 \mathrm{sfu}$. Further, in summer $f o \mathrm{~F} 2$ and $f o \mathrm{~F} 3$ values are found to be lower than those in other seasons. The saturation phenomenon in $f o \mathrm{~F} 2$ for $F_{10.7}>\sim 120 \mathrm{sfu}$ is different from that reported for the mid-latitudes where saturation has been seen for $F_{10.7}>200 \mathrm{sfu}$.

6. Variations in $f o \mathrm{~F} 2$ show dominant periods of $\sim 27$ days, $\sim 16$ days and $\sim 6$ days. The amplitude of $\sim 27$-day variations in $f o \mathrm{~F} 2$ is found to be minimum in HSA despite the highest amplitude of $\sim 27$-day variations in $F_{10.7}$, indicating that the direct effect of solar rotation on $f o \mathrm{~F} 2$ is minimum in HSA. During HSA, however, $\sim 27$-day variations in $\Delta H$ are found to have a close relationship with those of $F_{10.7}$ when compared to those in LSA and MSA, implying that $\sim 27$-day variations in $f o \mathrm{~F} 2$ in HSA may be partly linked with electrodynamical variations (as seen in $\Delta H)$.

Acknowledgements. P. Pavan Chaitanya gratefully thanks NARL for supporting his research through a research fellowship. N. Balan thanks the Japan Society for the Promotion of Science (JSPS) for the Invitation Fellowship.

The topical editor H. Kil thanks H. Chandra and one anonymous referee for help in evaluating this paper.

\section{References}

Abdu, M. A., Ramkumar, T. K., Batista, I. S., Brum, C. G. M., Takahashi, H., Reinisch, B. W., and Sobral, J. H. A.: Planetary wave signatures in the equatorial atmosphere-ionosphere system, and mesosphere- E- and F-region coupling, J. Atmos. Sol.-Terr. Phys., 68, 509-522, 2006.
Anderson, D. N., Anghel, A., Yumoto, K., Ishitsuka, M., and Kudeki, E.: Estimating daytime vertical ExB drift velocities in the equatorial F-region using ground-based magnetometer observations, Geophys. Res. Lett., 29, 37-1-37-4, doi:10.1029/2001GL014562, 2002.

Balan, N., Bailey, G. J., Jenkins, B., Rao, P. B., and Moffett, R. J.: Variations of ionospheric ionization and related solar fluxes during an intense solar cycle, J. Geophys. Res., 99, 2242-2253, 1994.

Balan, N., Batista, I. S., Abdu, M. A., MacDougall, J., and Bailey, G. J.: Physical mechanism and statistics of occurrence of an additional layer in the equatorial ionosphere, J. Geophys. Res., 103, 29169-29181, doi:10.1029/98JA02823, 1998.

Bilitza, D.: International reference ionosphere 2000, Radio Sci., 36, 261-275, 2001.

Bilitza, D. and Reinisch, B. W.: International Reference ionosphere 2007: Improvements and new results, Adv. Space Res., 42, 599609, 2007.

Bilitza, D., McKinnell, L., Reinisch, B. W., and Fuller-Rowell, T.: The international reference ionosphere today and in the future, J. Geod., 85, 909-920, doi:10.1007/s00190-010-0427-x, 2011.

Bilitza, D., Altadill, D., Zhang, Y., Mertens, C., Truhlik, V., Richards, P., McKinnell, L.-A., and Reinisch, B.: The International Reference Ionosphere 2012 - a model of international collaboration, J. Space Weather Space Clim., 4, A07, doi:10.1051/swsc/2014004, 2014.

Chandra, H. and Rastogi, R. G.: General features of the ionosphere at Thumba, J. Inst. Telecomm. Eng., 17, 207-216, 1971.

Chau, J. L., Goncharenko, L. P., Fejer, B. G., and Liu, H.-L.: Equatorial and low latitude ionospheric effects during sudden stratospheric warming events, Space. Sci. Rev., 168, 385-417, doi:10.1007/s11214-011-9797-5, 2011.

Chen, Y. and Liu, L.: Further study on the solar activity variation of daytime $N m \mathrm{~F} 2$, J. Geophys. Res., 115, A12337, doi:10.1029/2010JA015847, 2010.

Dabas, R. S., Sharma, N., Pillai, M. G. K., and Gwal, A. K.: dayto-day variability of equatorial and low latitude F-region ionosphere in the Indian zone, J. Atmos. Sol-Terr. Phy., 68, 12691277, 2006.

Forbes, J. M., Palo, S. E., and Zhang, X.: Variability of the ionosphere, J. Atmos. Sol-Terr. Phy., 62, 685-693, 2000.

Hagan, M., Maute, A., and Roble, R.: Tropospheric tidal effects on the middle and upper atmosphere, J. Geophys. Res., 114, A01302, doi:10.1029/2008JA013637, 2009.

Immel, T. J., Sagawa, E., England, S. L., Henderson, S. B., Hagan, M. E., Mende, S. B., Frey, H. U., Swenson, C. M., and Paxon, L. J.: Control of equatorial ionospheric morphology by atmospheric tides, Geophys. Res. Lett., 33, L15108, doi:10.1029/2006GL026161, 2006.

Lee, C. C.: Examination of the absence of noontime bite-out in equatorial total electron content, J. Geophys. Res., 117, A09303, doi:10.1029/2012JA017909, 2012

Lee, C. C. and Reinisch, B. W.: Variations in equatorial F2-layer parameters and comparison with IRI-2007 during a deep solar minimum, J. Atmos. Sol-Terr. Phy., 74, 217-223, 2012.

Lee C. C., Reinisch, B. W., Su, S.-Y., and Chen, W. S.: Quiet-time variations of F2-layer parameters at Jicamarca and comparison with IRI-2001 during solar minimum, J. Atmos. Sol-Terr. Phy., 70, 184-192, 2008. 
Ma, R., Xu, J., Wang, W., and Lei, J.: The effect of $\sim 27$ day solar rotation on ionospheric $\mathrm{F} 2$ region peak densities $(\mathrm{NmF} 2)$, J. Geophys. Res., 117, A03303, doi:10.1029/2011JA017190, 2012.

Pancheva, D., Mukhtarov, P. J., Shepherd, M. G., Mitchell, N. J., Fritts, D. C., Riggin, D. M., Franke, S. J., Batista, P. P., Abdu, M. A., Batista, I. S., Clemesha, B. R., and Kikuci, T.: Two day wave coupling of the low-latitude atmosphere-ionosphere system, J. Geophys. Res., 111, A7313, doi:10.1029/2005JA011562, 2006.

Pasricha, P. K., Aggarwal, S., and Reddy, B. M.: Estimation of the hourly variability of $f o \mathrm{~F} 2$ at a low-latitude station, Radio Sci., 22, 125-132, 1987.

Patra, A. K., Chaitanya, P. P., Mizutani, N., Otsuka, Y., Yokoyama, T., and Yamamoto, M.: A comparative study of equatorial daytime vertical ExB drift in the Indian and Indonesian sectors based on $150 \mathrm{~km}$ echoes, J. Geophys. Res., 117, A11312, doi:10.1029/2012JA018053, 2012.

Patra, A. K., Pavan Chaitanya, P., Sripathi, S., and Alex, S.: Ionospheric variability over Indian low latitude linked with the 2009 sudden stratospheric warming, J. Geophys. Res.-Space, 119, 4044-4061, doi:10.1002/2014JA019847, 2014.

Pavan Chaitanya, P., Patra, A. K., and Rao, S. V. B.: Contrasting features of the F3 layer during high and low solar activity conditions observed from Indian low latitude, Indian J. Radio Space, 41, 121-129, 2012.

Radicella, S. M. and Adeniyi J. O.: Equatorial ionospheric electron density below the F2 peak, Radio Sci., 34, 1153-1163, doi:10.1029/1999RS900071, 1999.

Rajaram, G.: Structure of the equatorial $F$ region, topside and bottomside- A review, J. Atmos. Terr. Phys., 39, 1125-1144, doi:10.1016/0021-9169(77)90021-6, 1977.
Rajaram, G. and Rastogi, R. G.: Equatorial electron densities- seasonal and solar cycle changes, J. Atmos. Terr. Phys., 39, 11751182, doi:1026/0021-9169(77)90026-5, 1977.

Rastogi, R. G. and Klobuchar, J. A.: Ionospheric electron content within the equatorial F2 layer anomaly belt, J. Geophys. Res., 95, 19045-19052, 1990.

Rastogi, R. G., Chandra H., Sharma R. P., and Rajaram G.: Groundbased measurements of ionospheric phenomena associated with equatorial electrojet, Indian J. Radio Space, 1, 119-135, 1972.

Rishbeth, H. and Mendillo, M.: Patterns of F2-layer variability, J. Atmos. Sol-Terr. Phy., 63, 1661-1680, 2001.

Sastri, J. H. and Ramesh, K. B.: Forenoon bite-out in $f o F 2$ at low latitudes, Indian J. Radio Space, 11, 81-82, 1982.

Sethi, N. K., Dabas, R. S., Singh, L., Vohra, V. K., Veenadhari, B., and Garg, S. C.: Results of $f o \mathrm{~F} 2$ and Ne-h profiles at low latitude using recent digital ionosonde observations and their comparison with IRI-2000, J. Atmos. Sol-Terr. Phy., 65, 749-755, 2003.

Sharma, S., Chandra, H., and Vyas, G. D.: Long term ionospheric trends over Ahmedabad, Geophys. Res., Lett., 26, 433-436, 1999.

Vikramkumar, B. T., Rao, P. B., Viswanathan, K. S., and Reddy, C. A.: Electric fields and currents in the equatorial electrojet deduced from VHF radar observations-III. Comparison of observed $\Delta H$ values with those estimated from measured electric fields, J. Atmos. Terr. Phys., 49, 201-207, 1987.

Yadav, S., Dabas, R. S., Das, R. M., Upadhayaya, A. K., Sharma, K., and Gwal, A. K.: Diurnal and seasonal variation of F2-layer ionospheric parameters at equatorial ionization anomaly crest region and their comparison with IRI-2001, Adv. Space Res., 45, 361-367, 2010.

Yadav, S., Dabas, R. S., Das, R. M., Upadhayaya, A. K., Sarkar, S. K., and Gwal, A. K.: Variation of F-region critical frequency ( $f o \mathrm{~F} 2)$ over equatorial and low latitude region of the Indian zone during 19th and 20th solar cycle, Adv. Space Res., 47, 124-137, 2011. 